\title{
Willkommen im Jahr des Hundes
}

Seit dem chinesischen Neujahr, dem 16.02.2018 nach unserem Kalender, leben wir im „Jahr des Hundes“.

Im Gegensatz zu unserem westlichen Zodiak mit 12 Tierkreiszeichen, die monatlich wechseln und nach einem Jahr den Kreislauf durchlaufen haben, gilt in der chinesischen Astrologie ein Tierkreiszeichen immer für ein Jahr. Auch hier gibt es 12 Tierkreiszeichen und erst nach 12 Jahren ist ein Zyklus vollendet. Aber das wissen Sie sicher.

Nun, der Hund ist das vorletzte Tier und dazu gibt es eine nette Legende: $D a$ nach wollte Buddha Neujahr feiern. Die Tiere waren geladen und machten sich auf den Weg. Als Erster traf der Büffel ein. Aber die Ratte, gemäß ihrem Charakter, ließ sich auf seinem Rücken transportieren und sprang vor dem Büffel auf den Boden. Sie war damit dann sozusagen Erste. Und so ist die Ratte das erste Tier im Jahreskreislauf vor dem Büffel. Der Hund war zwar schnell, als guter Läufer vorne dran, aber zuletzt mussten alle Tiere durch einen Fluss. In diesem Fluss hatte der Hund dermaßen viel Spaß, plantschte und tobte fröhlich drin herum, sodass er beinahe die Einladung Buddhas vergaß. Erst in letzter Sekunde rannte er noch mal los, um rechtzeitig bei Buddha zu sein. Unterwegs überholte er dann immerhin noch das langsamere Schwein.

Sympathisch, der Hund, wenn Sie mich fragen. Aber der chinesische Tierzyklus ist noch komplizierter! $\mathrm{Zu}$ jedem Jahr und zu jedem Tier wird auch noch eines der fünf Elemente zugeordnet. Und so ist ein Zyklus erst nach $5 \times 12$ Jahren, also nach 60 Jahren vollendet. Wer also in diesem Jahr sein 60. Lebensjahr vollendet, hat einen kompletten Zyklus durchlaufen und ist der Vollendung ein Stück näher gerückt. In diesem Jahr sind also der

Deutsche Zeitschrift für Akupunktur

2018 - 61 (2): 122

https://doi.org/10.1007/s42212-018-0034-y

Online publiziert: 20. März 2018

(c) Springer Medizin Verlag $\mathrm{GmbH}$, ein Teil von

Springer Nature 2018
Hund und das Element Erde dran. Also: Willkommen im Jahr des Erd-Hundes!

Die Farbe des Erd-Hundes ist normalerweise gelb, dieses Jahr braun. Eine Erklärung dafür habe ich nicht gefunden. Und er repräsentiert mit seinem Symbol (戊 $\mathrm{Xu}$ ) etwas Erdiges (aus den 12 Erdstämmen, nach denen die Tageszeit eingeteilt wurde), also er ist besonders erdig, obwohl ihm sonst meist das Element "Metall“ zugeordnet wird. Dieses Jahr ist also ein sehr hündisches Hundejahr, Hund in Potenz sozusagen.

Erd-Hunde-Jahre sollen eine günstige Zeit für Erfindungen sein, bei denen man Risiken eingehen muss. Agile erfinderische Köpfe, Mut und Draufgängertum sind auf der Gewinnerseite. Unter dem Einfluss des Hundes werden diese Unternehmungen erfolgreich sein! Aber neben der Kreativität bestimmt natürlich auch Chaos das Jahr. Aber natürlich findet man auch das genaue Gegenteil in den Voraussagen!

Die Stärken der in den Erd-HundeJahren Geborenen sollen Treue, Mitmenschlichkeit, Zuverlässigkeit, Vertrauenswürdigkeit und Großzügigkeit sein. Die Schwächen Sturheit, Zynismus, Egozentrik (oder Altruismus nach anderen Quellen) und aufbrausendes Wesen. Es wird ihnen eine gewisse Introvertiertheit nachgesagt. Und ein ausgesprochener Sinn für Gerechtigkeit.

Sie eignen sich angeblich besonders gut als Ärzte und Medizinprofessoren und haben viel soziales Talent. Also wenn Sie noch in jungen Jahren sind und einen Praxisnachfolger (sozusagen maßgeschneidert) haben wollen, sollten Sie sich beeilen. Auch das Erd-Hunde-Jahr hat nur 12 Monate und es gilt das Jahr der Geburt, nicht der Zeugung!

Dabei erinnere ich mich an eine Patientin, die mir erzählte, dass sie für ihren Sohn ein Horoskop hatte erstellen lassen kurz nach seiner Geburt. Die Astrologin vermutete, dass aus ihm ein Schriftsteller werden würde. Der Junge saß neben uns und malte mit Hingabe und mit einer für einen Achtjährigen erstaunlichen technischen Detailtreue Bagger, Kräne und Baumaschinen. Also vielleicht wird er tech- nische Bücher schreiben. Und vielleicht hätten auch Sie Pech und es wird nichts aus der Praxisnachfolge, weil das Kind lieber Lehrer, Rechtsanwalt oder Geheimagent wird? Und wenn Sie meine Darlegungen überprüfen wollen, schauen Sie sich doch einfach im Jahr 1958 Geborene an. Das sind vermutlich die einzigen ErdHunde, die Sie beobachten können, es sei denn, Sie kennen jemanden, der aus dem Jahr 1898 stammt.

Tja, was fangen wir nun mit dem Jahr des Erd-Hundes an?

Das Chaos in der Politik hält uns in Atem oder gibt nur noch zu einem resignierten Gähnen Anlass, als praktisch Arbeitende sind wir an aufsehenerregenden Erfindungen kaum beteiligt, wilde Spekulationen z. B. auf dem Aktienmarkt haben nur selten Glück und Reichtum gebracht. Aber Spaß haben, daran sollten wir öfter denken. Und uns ein Beispiel am Hund nehmen und das Jahr genießen.

\section{Korrespondenzadresse}

\section{Dr. Cornelia Tauber-Bachmann} Wasserloser Str. 32, 63755 Alzenau, Deutschland

Interessenkonflikt. C. Tauber-Bachmann gibt an, dass kein Interessenkonflikt besteht. 